\title{
Deeper-Layer Body Tissue Temperature Control Using Multi-Sensory Transducer
}

\author{
Audrone Dumciene ${ }^{1}$, Saule Sipaviciene ${ }^{2}$ \\ ${ }^{1}$ Department of Heath, Physical and Social Education, Lithuanian Sports University, \\ Sporto St. 6, LT-44221 Kaunas, Lithuania \\ ${ }^{2}$ Department of Applied Biology and Rehabilitation, Lithuanian Sports University, \\ Sporto St. 6, LT-44221 Kaunas, Lithuania \\ audrone.dumciene@lsu.lt
}

\begin{abstract}
For the monitoring of deeper layers of human tissue temperature during cooling the four-thermistor transducer was proposed. The Steinhart-Hart equation was used to linearize the temperature-resistance characteristics of thermistors. Transducer structure and temperature fields in the tissues of the body were simulated using COMSOL Multiphysics. The ratio of transducer's equivalent thermal resistances was determined using numerical and physical experiments.

The difference of values of the temperature measured at a depth of $30 \mathrm{~mm}$ in tissue by invasive and non-invasive method was less than $\pm 0.5^{\circ} \mathrm{C}$.
\end{abstract}

Index Terms-Tissue, thermistor, measurement, temperature.

\section{INTRODUCTION}

For human body temperature measurement many methods can be used. These methods are classified into two main groups: invasive and non-invasive methods of measurement.

Invasive methods are associated with the introduction of the temperature sensor into the body at natural body cavities. Commonly, the core body temperature is most accurately measured using the Schwan-Ganz catheter inserted in the pulmonary artery or when measuring oesophageal temperature by inserting the probe through a nostril. This method is accepted as the "gold standard" for core temperature $37{ }^{\circ} \mathrm{C} \pm 0.6{ }^{\circ} \mathrm{C}$ [1]. However, these methods and equipment in practice can be used only under clinical conditions.

Non-invasive methods and devices have been proposed and are produced in quite a various types [2], [3], based on a so-called zero-flux method for which a source of energy is required for the attainment of thermal equilibrium. There are devices operating in a so-called double sensor principle [4], [5].

A double sensor technology [4] exists, which does not require an additional heat source. However, the amount of heat loss through the surface of the sensor requires an additional measurement of the temperature on the surface of sensor and the thermal characteristics of sensor material have to be assessed as well.

The temperature of the deep muscle layers is need to know by testing muscle capability for work, when their

Manuscript received April 18, 2015; accepted August 16, 2015. temperature is below $36.6{ }^{\circ} \mathrm{C}$ or during muscle trauma treatment with ice pack.

We take the hypothesis, that it is possible to form two potentially similar heat flows from a human body through temperature transducer's channels relation to small lengths of this channels and a small differences of sensors body and channels material's thermal conductivity.

\section{Methods AND SAMPLES}

The structure of the proposed transducer (thermal energy convert into electrical energy) and temperature sensor arrangement is shown in Fig. 1.

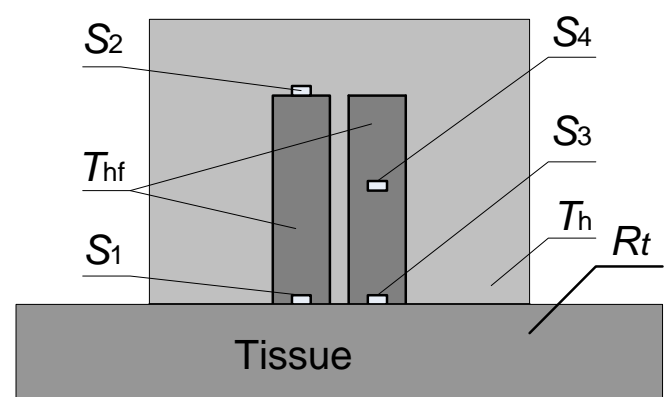

Fig. 1. Transducer structure. Here $S_{1}, S_{2}, S_{3}, S_{4}$ - temperature sensors; $T_{\mathrm{h}}-$ thermo-insulation; $T_{\mathrm{hf}}$ - thermo-insulation channel; Tissue - human body tissue (skin, fat, muscle); $R_{\mathrm{t}}-$ tissue thermal resistance.

Thermal equivalent circuit of transducer is shown in Fig. 2.

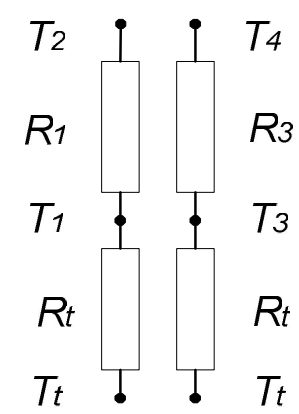

Fig. 2. Equivalent resistances circuit of two heat flow channels. Here $T_{\mathrm{t}}$ body tissue temperature, $T_{1}$ - sensor's $S_{1}$ temperature, $T_{2}$ - sensor's $S_{2}$ temperature, $T_{3}-$ sensor's $S_{3}$ temperature, and $T_{4}-$ sensor 's $S_{4}$ temperature, $R_{\mathrm{t}}$ - tissue thermal resistance, $R_{1}$ - thermal resistance of first thermal channel, $R_{2}$ - thermal resistance of second thermal channel.

From the equivalent circuit in Fig. 2 the heat flow through the first channel can be expressed as (1) 


$$
F_{1}=\frac{T_{t}-T_{1}}{R_{t}}=\frac{T_{1}-T_{2}}{R_{1}},
$$

and for the second channel heat flow is (2)

$$
F_{2}=\frac{T_{t}-T_{3}}{R_{t}}=\frac{T_{3}-T_{4}}{R_{2}} .
$$

We take the assumption that if both parallel heat propagation channels are hypothetically under analogous conditions, we can negate the non-identity error and assume that $F_{1}=F_{2}=F$, which can be expressed as (3)

$$
F=\frac{T_{t}-T_{1}}{R_{t}}=\frac{T_{1}-T_{2}}{R_{1}}=\frac{T_{t}-T_{3}}{R_{t}}=\frac{T_{3}-T_{4}}{R_{2}},
$$

We can from (3) to calculate the temperature $T_{\mathrm{t}}$ as (4)

$$
T_{t}=\frac{T_{1} \frac{R_{1}}{R_{2}}\left(T_{3}-T_{4}\right)-T_{3}\left(T_{1}-T_{2}\right)}{\frac{R_{1}}{R_{2}}\left(T_{3}-T_{4}\right)-\left(T_{1}-T_{2}\right)} .
$$

By assigning ratio $R_{1} / R_{2}=\alpha$, it is possible to restate (4) as (5)

$$
T_{t}=\frac{T_{1} \alpha\left(T_{3}-T_{4}\right)-T_{3}\left(T_{1}-T_{2}\right)}{\alpha\left(T_{3}-T_{4}\right)-\left(T_{1}-T_{2}\right)} .
$$

The coefficient $\alpha$ can be determined in two ways: using numerical or physical experiment. Numerical experiment can be conducted by analysing the heat propagation process in body tissue.

The heat propagation process in living tissues can be described by Penne's equation [6]. Thus the bioheat transfer process taking place in skin, subcutaneous tissue and muscles can be described by Penne's equation (6) [6]

$\delta_{t s} \rho C \frac{\delta T}{\delta t}+\nabla \times(-k \nabla T)=\rho_{b} C_{b} \omega_{b}\left(T_{b}-T\right)+Q_{m}+Q_{e x}$,

where $\delta_{t s}$ - a time-scaling coefficient; $\rho-$ the tissue density $\left(\mathrm{kg} / \mathrm{m}^{3}\right) ; C-$ the specific heat of tissue $(\mathrm{J} /(\mathrm{kg} \mathrm{K})) ; k-$ the tissue's thermal conductivity tensor $(\mathrm{W} /(\mathrm{m} \mathrm{K})) ; \rho_{b}-$ the density of blood $\left(\mathrm{kg} / \mathrm{m}^{3}\right) ; C_{b}-$ the specific heat of blood $(\mathrm{J} /(\mathrm{kg} \mathrm{K})) ; \omega_{b}-$ the blood perfusion rate $(1 / \mathrm{s}) ; T_{b}-$ the arterial blood temperature $(\mathrm{K}) ; Q_{m e t}-$ the heat source from metabolism $\left(\mathrm{W} / \mathrm{m}^{3}\right) ; Q_{e x}$ - the spatial heat source $\left(\mathrm{W} / \mathrm{m}^{3}\right)$.

In case of thermal equilibrium condition and absence of spatial heat sources inside tissues, (6) can be written as

$$
\nabla \times(-k \nabla T)=\rho_{b} C_{b} \omega_{b}\left(T_{b}-T\right)+Q_{m} .
$$

Boundary sources and constraints: continuity on the entire interior boundary

$$
\vec{n} \times\left(k_{1} \nabla T_{1}-k_{2} \nabla T_{2}\right)=0 .
$$

Symmetry condition, used to reduce model size by taking advantage of symmetry

$$
-\vec{n} \times(-k \nabla T)=0,
$$

Bioheat transfer model properties [7] used in modelling are given in Table I, bioheat equation inputs are provided in Table II, and the core body temperature $T_{c}=37^{\circ}$ (310.15 K).

TABLE I. TISSUE LAYERS' PROPERTIES.

\begin{tabular}{|c|c|c|c|c|}
\hline Layer & $\boldsymbol{\rho}\left(\mathbf{k g} / \mathbf{m}^{\mathbf{3}}\right)$ & $\boldsymbol{k},\left(\mathbf{W} / \mathbf{m}^{*} \mathbf{K}\right)$ & $\boldsymbol{C p},(\mathbf{J} / \mathbf{k g} * \mathbf{K})$ & Thickness, $\mathbf{~}$ \\
\hline Skin & $1109 \pm 14$ & $0.37 \pm 0.06$ & $3391 \pm 233$ & 0.002 \\
\hline Fat & $911 \pm 53$ & $0.21 \pm 0.02$ & $2348 \pm 372$ & 0.0025 \\
\hline Muscle & $1090 \pm 52$ & $0.49 \pm 0,04$ & $3421 \pm 460$ & 0.15 \\
\hline Blood & $1050 \pm 17$ & $0.58 \pm 0,05$ & $3617 \pm 301$ & \\
\hline Bone & $1908 \pm 133$ & $0.32 \pm 0.03$ & $1313 \pm 295$ & 0.03 \\
\hline
\end{tabular}

TABLE II. BIOHEAT EQUATION INPUTS.

\begin{tabular}{|c|c|c|c|}
\hline Tissue & $\boldsymbol{Q}_{\text {met }}\left(\mathbf{W} / \mathbf{m}^{\mathbf{3}}\right)$ & $\boldsymbol{\omega}_{\mathbf{b}}(\mathbf{1} / \mathbf{s})$ & $\boldsymbol{T}_{\text {body }}(\mathbf{K})$ \\
\hline Skin & 4 & $7.2 \mathrm{e}-8$ & 310.15 \\
\hline Fat & 0 & $4.5 \mathrm{e}-6$ & 310.15 \\
\hline Muscle & 5 & 0,0001 & 310.15 \\
\hline Blood & & 0.5 & 310.15 \\
\hline Bone & & $6.5 \mathrm{e}-7$ & 310.15 \\
\hline
\end{tabular}

Precision thermistors type MF51E103F3380 which are intended for medical equipment were used as temperature sensors [8]. The Steinhart-Hart equation interpolation (10) was used for the description of the thermistor's temperature resistance $R(T)$ characteristics [9]

$$
1 / T=A_{0}+A_{1} \ln R_{T}+A_{3}\left(\ln R_{T}\right)^{3},
$$

where $R_{\mathrm{T}}$ - the thermistor resistance at the temperature $T, T$ - the temperature in $\mathrm{K}$, and $A_{0}, A_{1}, A_{3}$ - coefficients.

Coefficients $A_{0}, A_{1}$, and $A_{3}$ were calculated from the thermistor calibration results. Thermistors additionally have been individually calibrated using two-point temperature thermistor calibration procedure [9]. The accuracy of the experimental transducer with thermistors for witch was used the Steinhart-Hart linearization was $\pm 0.02{ }^{\circ} \mathrm{C}$.

The transducer's simulation results were verified experimentally using a physical model. Peltier element was used as the heat source imitating human body. The temperature was controlled with accuracy $\pm 0.1{ }^{\circ} \mathrm{C}$ using a precision thermocouple.

The Peltier element was positioned under $30 \mathrm{~mm}$ thick high density polyethylene plate, with thermal conductivity $k=0.42 \mathrm{~W} / \mathrm{m} \mathrm{K}$ to $0.51 \mathrm{~W} / \mathrm{m} \mathrm{K}$ [10], as it is similar to the muscle thermal conductivity (see Table I). Reference temperature was determined and maintained at $32 \pm 0.1^{\circ} \mathrm{C}$. Temperature of transducer's thermistors was measured only after 60 minutes after the temperature of the Peltier element reached the target value in order to stabilize the flow of heat.

The reference temperature under transducer was measured using FLUKE type 5610 thermistor (serial No A6B0211 absolute accuracy in $0 \ldots 100{ }^{\circ} \mathrm{C}$ temperature range is not worse than $0.015{ }^{\circ} \mathrm{C}$ ), the thermometer FLUKE type Black Stack 1560 and type 2564 Thermistor readout module.

The experiment involved 5 male volunteers - university students - aged $23.4 \pm 1.6$ years, height $181.4 \pm 4.1 \mathrm{~cm}$, 
weight $78.7 \pm 2.4 \mathrm{~kg}$. All experiments were performed according to the Helsinki Declaration adopted for ethical principles of experiments involving human beings. The study protocol was approved by the Kaunas regional biomedical research ethics committee.

Muscle temperature was measured with a needle thermometer type MKA (Ellab A/S, type DM 852, Denmark). Skin surface temperature was measured by surface thermometric sensor type MHA (Ellab A/S, type DM 852, Denmark).

Person under investigation procedure remained still for 15 minutes at room temperature of $20{ }^{\circ} \mathrm{C}-22{ }^{\circ} \mathrm{C}$. The control measurements of muscle temperature and skin surface temperature were conducted before cooling.

The needle temperature sensor $3 \mathrm{~cm}$ long was put into the broad side of the thigh muscle (musculus Vastus lateralis), the middle-third from the side of the hip. The $3 \mathrm{~cm}$ depth of temperature measurement is considered as a reference point of living muscle temperature [11].

Muscle temperature and skin surface temperature were measured immediately after muscle cooling. Needle thermometer was sterilized in an autoclave after each use. The skin surface measuring points were located near the needle thermometer measuring points.

\section{RESULTS AND DISCUSSIONS}

The results of temperature field distribution simulation using COMSOL Multiphysics for illustration are shown in Fig. 3.

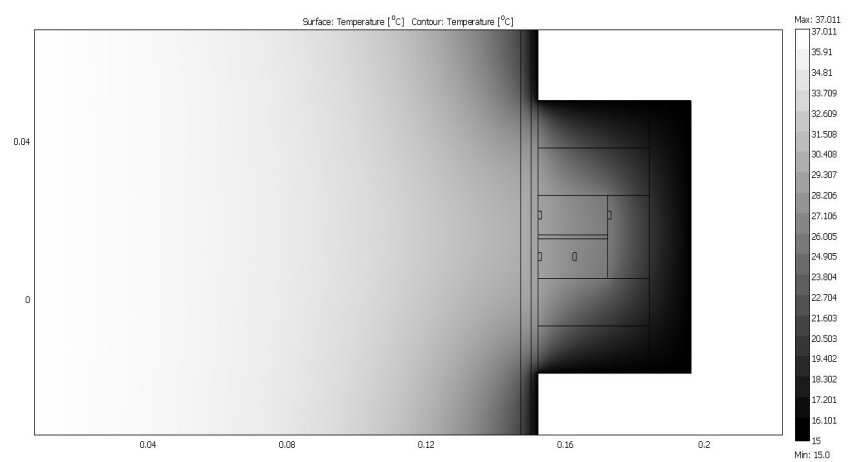

Fig. 3. Distribution of temperature fields in tissues and in tissues under temperature transducer (deep in $\mathrm{m}$ ), under environment temperature $+15^{\circ} \mathrm{C}$.

The reduction of heat loss from transducer surface is very important for measurement accuracy and it can be minimized by choosing a proper thermal insulation cover. In this case, a polyurethane foam (material type Thermaflex) was used for modelling and to produce an experimental transducer, with a thermal conductivity $k=0.028 \mathrm{~W} / \mathrm{m} \times \mathrm{K}$. In order to correctly select temperature sensors' locations inside the transducer body, it is necessary to choose a proper thermal resistance ratio $R_{1} / R_{2}$.

Skin surface temperature calculation results obtained using (5), different $R_{1} / R_{2}$ relationship values and the temperature field simulation data are presented in Fig. 4.

According to the simulation results, the ratio $R_{1} / R_{2}$ was selected equal to five. Changing this ratio 4 to 6 , the calculated value of surface temperature increased only by $0.02 \%$. Thus, the ratio of resistances can be selected equal to five and this value can be used in transducer design.

Data from the thermistors' resistance measurement gauges was transmitted to analog-to-digital converters and passed in digital form to computer for data processing.

According to the results of numerical simulation under the ambient temperature of $20{ }^{\circ} \mathrm{C}$, the temperature under transducer (skin surface) was $T_{\mathrm{s}}=30.04{ }^{\circ} \mathrm{C}$, while the value of the measured temperature on the physical model using experimental transducer was $30 \pm 0.28{ }^{\circ} \mathrm{C}$ (measurements repeated five times). When the ambient temperature was $15^{\circ} \mathrm{C}$, the simulated temperature under the transducer was $T_{\mathrm{s}}=27.99{ }^{\circ} \mathrm{C}$, and the experimental average value of the measured temperature was $28 \pm 0.31{ }^{\circ} \mathrm{C}$ (measurements repeated five times as well).

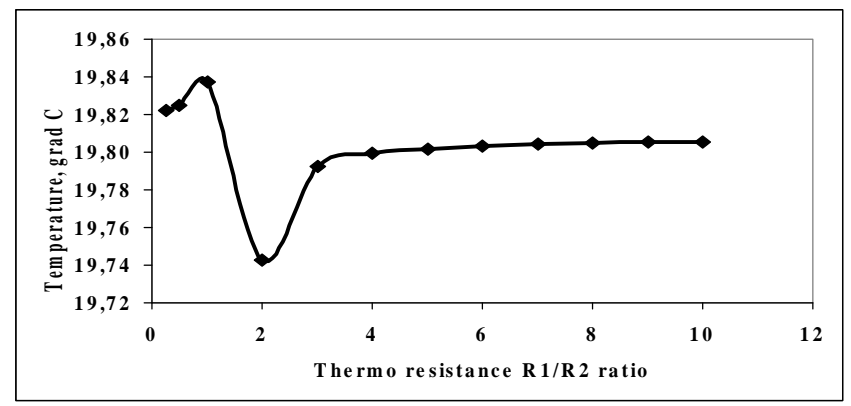

Fig. 4. Surface temperature dependence in respect of the ratio R1/R2.

Using the measured value of temperature under transducer $T_{\mathrm{s}}$, we can calculate the tissue temperature at a required depth from the skin surface. A suitable equation can be composed using numerical simulation data. Data approximation error was evaluated by calculating the sum of squared deviations $S_{\mathrm{Sq}}$. By using the second-order polynomial, the value of squared deviations was $S_{\mathrm{Sq}}=$ 0.1711 ; when using sixth-order polynomials, the value of squared deviations was $S_{\mathrm{Sq}}=0.003958$. It is therefore appropriate to use the sixth-order polynomials for approximation. Residual plot of deviations after approximation using sixth order polynomial is shown in Fig. 5.

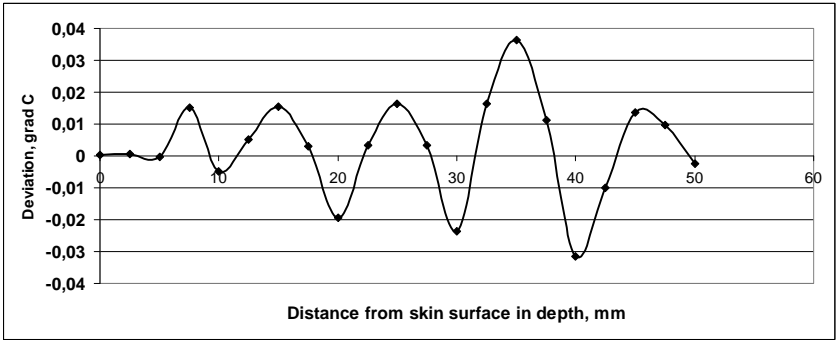

Fig. 5. Residual plot of deviations after approximation using sixth order polynomial.

Using proposed transducer for measurement of skin surface temperature, it is possible to control the temperature of the deeper layers of tissue over the entire duration of limb cooling in cold water, and, for example, to calculate the muscle temperature at a depth of $3 \mathrm{~cm}$ using the equation (10)

$$
T_{3 \mathrm{~cm}}=0.5026 \times T s+18.399 .
$$

The relation between the skin surface temperature under 
transducer and the temperature of the tissue at $3 \mathrm{~cm}$ below the surface is shown in Fig. 6.

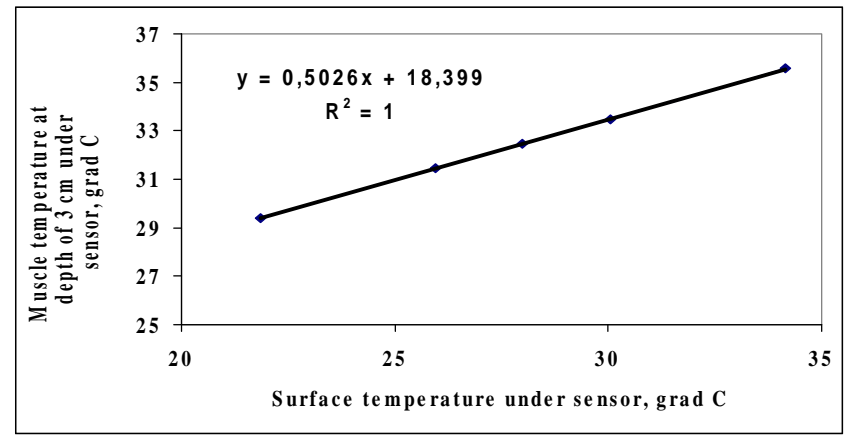

Fig. 6. The dependence of the tissue temperature at a depth of $3 \mathrm{~cm}$ in respect of the skin surface temperature after cooling.

Non-invasive temperature measurement means and method of calculation have been verified by comparing temperature measurements at $3 \mathrm{~cm}$ depth following cooling of limbs in cold water bath at $15{ }^{\circ} \mathrm{C}$ for 30 minutes.

Before cooling, muscle temperature was $36.4 \pm 0.46{ }^{\circ} \mathrm{C}$ and skin surface temperature was $30.7 \pm 0.6{ }^{\circ} \mathrm{C}$.

The temperature of deep layers was measured with a needle sensor at a point displaced by $2 \mathrm{~cm}$ from transducer point in order not to distort the results (see Fig. 3).

Muscle temperature at a depth of $3 \mathrm{~cm}$ measured using the proposed set of measurement tools and techniques was $32.47 \pm 0.6{ }^{\circ} \mathrm{C}$, while the value measured using a needle thermometer was $32.1 \pm 0.4{ }^{\circ} \mathrm{C}$.

It is problematic to ensure the accuracy of measurement using a needle thermometer, because the accuracy of the needle-probe placement depth is approximately $\pm 0.5 \mathrm{~mm}$. The digital simulation revealed that an error of $\pm 0.5 \mathrm{~mm}$ in determining the depth of needle-stick thermometer can produce $\pm 0.74{ }^{\circ} \mathrm{C}$ temperature measurement error at a depth of $3 \mathrm{~cm}$ in muscle tissue.

In this study, the difference of the temperature measurement results obtained in deeper layers of tissue using two methods was $0.37{ }^{\circ} \mathrm{C}$ and this difference is no higher than that obtained by other authors by measuring the temperature of the body in different ways [1]-[3].

Under ice cooling pack [12], the temperature was measured only in the subcutaneous layer; in this way direct comparison of our results would be incorrect. Still, the simulation results obtained in this study within $\pm 0.5{ }^{\circ} \mathrm{C}$ coincide with temperature values specified in study [12], obtained after $30 \mathrm{~min}$ cooling with fine ice package elastic band secured to a limb.

\section{CONCLUSIONS}

Use of the proposed design of temperature transducer containing four precision thermistors is a novel non-invasive way to determine the temperature of the deeper layers of tissue. To ensure the body tissue temperature measurement accuracy, the transducer must be covered using a cap with good thermal insulation that minimizes the influence of ambient temperature.

Transducer attached to the body using an elastic band can be immersed into the cold water bath while remaining attached to the limb over the entire cooling time required by the muscle temperature control procedure.

\section{ACKNOWLEDGMENT}

The authors would like to thank the colleagues from the Metrology Institute Kaunas University of Technology for their assistance in producing transducer and conducting experiments.

\section{REFERENCES}

[1] O. Kimberger, R. Thell, M. Schuh, J. Koch, D. I. Sessler, A. Kurz, "Accuracy and precision of a novel non-invasive core thermometer", British Journal of Anaesthesia, vol. 103, no. 2, pp. 226-231, 2009. [Online] Available: http://dx.doi.org/10.1093/bja/aep134

[2] L. P. J. Teunissen, J. Klewer, A. de Haan, J. J. de Koning, H. A. M. Daanen, "Non-invasive continuous core temperature measurement by zero heat flux", Physiological measurement, vol. 32, pp. 559-570, 2011. [Online] Available: http://dx.doi.org/10.1088/0967$3334 / 32 / 5 / 005$

[3] L. N. Steck, E. M. Sparrow, J. P. Abraham, "Non-invasive measurement of the human core temperature", Int. J. Heat and Mass Transfer, vol. 54, pp. 975-982, 2011. [Online] Available: http://dx.doi.org/10.1016/j.ijheatmasstransfer.2010.09.042

[4] H. C. Gunga, A. Werner, A. Stahn, M. Steinach, T. Schlabs, E. Koralewski, D. Kunz, D. L. Belavy, D. Felsenberg, F. Sattler, J. Koch, "The Double Sensor - A non-invasive device to continuously monitor core temperature in humans on earth and in space", Respiratory Physiology \& Neurobiology, vol. 169, no. 1, pp. 63-68, 2009. [Online] Available: http://dx.doi.org/10.1016/j.resp. 2009.04.005

[5] K. I. Kitamuraa, X. Zhu, W. Chen, T. Nemoto, "Development of a new method for the noninvasive measurement of deep body temperature without a heater", Medical Engineering \& Physics, vol. 32, pp. 1-6, 2010. [Online] Available: http://dx.doi.org/ 10.1016/j.medengphy. 2009.09.004

[6] A. Lakhssassi, E. Kengne, H. Semmaoui, "Modifed pennes' equation modeling bio-heat transfer in living tissues: analytical and numerical analysis", Natural Science, vol. 2, no. 12, pp. 1375-1385, 2010. [Online] Available: http://dx.doi.org/10.4236/ns.2010.212168

[7] R. L. McIntosh, V. Anderson, "A comprehensive tissue properties database provided for the thermal assessment of a human at rest", Biophysical Reviews and Letters, vol. 5, no. 3, pp. 129-151, 2001. [Online] Available: http://www.itis.ethz.ch/assets/Downloads/ TissueDb/Files201 40801/DB_excel_20140801.xls

[8] MF51E High Precision NTC Thermistors for Extremely Accurate Temperature Measurement. Cantherm, Montreal, Canada, Montreal. 2006. [Online] Available: http://www.cantherm.com/products/ thermistors/mf51e.html

[9] A. Dumcius, S. V. Augutis, D. Gailius, "The approximation aspects of characteristics of semiconductor temperature sensors", Elektronika Ir Elektrotechnika, vol. 6, no. 112, pp. 47-50, 2011. [Online] Available: http://dx.doi.org/10.5755/j01.eee.112.6.443

[10] The Engineering Tool Box. [Online] Available: http://www engineeringtoolbox.com/thermal-conductivity-d_429.html

[11] A. J. Sargeant, "Effect of muscle temperature on leg extension force and short-term power output in humans", Eur J Appl Physiol, vol. 56, pp. 693-698, 1987. [Online]. Available: http://dx.doi.org/10.1007/ BF00424812

[12] D. Tomchuk, M. D. Rubley, W. R. Holcomb, M. Guadagnoli, J. M. Tarno, "The magnitude of tissue cooling during cryotherapy with varied types of compression", Journal of Athletic Training, vol. 45, no. 3, pp. 230-237, 2010. [Online] Available: http://dx.doi.org/10.4085/1062-6050-45.3.230 